\title{
Histological changes associated with fibroadenoma breast
}

\author{
Suman Singh ${ }^{1, *}$, Meenakshi Khajuria², Rashmi Kaul ${ }^{3}$, Adarsh Chauhan ${ }^{4}$, Rakesh Panwar $^{5}$ \\ ${ }^{\mathbf{1}}$ Assistant Professor, Dept. of Pathology, Dr. Rajendra Prasad Government Medical College, Kangra, Himachal, ${ }^{2}$ Medical \\ Officer, Jammu and Kashmir Health Services, ${ }^{3}$ Professor, Dept. of Pathology, Dr. Rajendra Prasad Government Medical College, \\ Kangra, Himachal, ${ }^{4}$ Senior Resident, Dept. of Pathology, Indira Gandhi Medical College, Shimla, Himachal, ${ }^{5}$ Senior Resident, \\ Dept. of Pathology, Dr YS Parmar Government Medical College, Nahan, Himachal Pradesh, India
}

*Corresponding Author: Suman Singh

Email: csuman9@gmail.com

\begin{abstract}
Introduction: Being the most common benign tumor of the breast, fibroadenoma show considerable histologic changes. It is important to highlight them as some of the changes are associated with increased risk of breast cancer.

Aims and Objectives: To study the pattern and histologic changes in fibroadenoma breast.

Materials and Methods: Retrospective analysis of histopathology of 55 cases of fibroadenoma breast diagnosed between Jan 2017 to Jun 2018. The pattern, epithelial and stromal changes were examined.

Result: Commonest age group involved was in 3rd decade. Pericanalicular pattern was the predominant pattern. Apocrine and cystic change was the commonest change in epithelium. Two cases $(3.6 \%)$ showed features of complex fibroadenoma. Three $(5.5 \%)$ cases showed foci of tubular adenoma. Epithelial hyperplasia was seen in 5(9\%) of cases of which 2 were mild, 2 were moderate and one was atypical hyperplasia. Inflammatory infiltrate in stroma was frequently observed.

Conclusion: Fibroadenoma showed variety of histological changes of which complex fibroadenoma and epithelial hyperplasia are significantly important which requires appropriate management and follow up.
\end{abstract}

Keywords: Fibroadenoma, Pattern, Histology, Changes.

\section{Introduction}

Fibroadenoma is commonest benign breast tumor and exhibit a wide range of cytologic and histologic variations. ${ }^{1,2}$ Peak incidence of fibroadenoma is in the $2^{\text {nd }}$ and $3^{\text {rd }}$ decade, although it can occur in any age group. ${ }^{4}$ Being biphasic tumor comprised of epithelial and stromal component, fibroadenoma display variations similar to normal breast..$^{2,3,5}$ Various studies highlighted the histopathological changes in fibroadenoma. ${ }^{1-5}$ Fibroadenoma with sclerosing adenosis, epithelial calcification, cyst greater than $3 \mathrm{~mm}$ in diameter or papillary apocrine change are termed as complex and are associated with high risk of invasive breast cancer. ${ }^{1}$ Also epithelial hyperplasia is a risk factor for breast carcinoma. ${ }^{1,3,8}$ Little literature is available regarding histopathological changes in fibroadenoma. In this backdrop, present study was undertaken to study and analyze morphological changes in fibroadenoma.

\section{Materials and Methods}

Present study was a retrospective study of 55 cases of fibroadenoma breast diagnosed in the department of pathology of tertiary care institute over a duration of one and a half year between January 2017 to June 2018 . The hemotoxylin and eosin stained histopathology slides of diagnosed cases of fibroadenoma breast were examined and analyzed for pattern and various histological change in stroma and epithelium of fibroadenoma.

\section{Results}

Fifty five cases of fibroadenoma were studied. It has been observed that commonest age group for fibroadenoma breast was $3^{\text {rd }}$ decade comprised of $20(37 \%)$ of cases followed by $2^{\text {nd }}$ and $4^{\text {th }}$ decade which comprised $14(25 \%)$ of cases each. Only $7(13 \%)$ cases were found in $5^{\text {th }}$ decade. Thirty five $(64 \%)$ cases showed involvement of right breast. Five (9\%) cases showed multiple fibroadenomas. Pericanalicular pattern was the predominant pattern in $36(65 \%)$ cases. Eleven were intracanalicular and 8 cases showed mixed pattern. Table 1. summarizes the various histological findings. Apocrine change was the commonest change observed in epithelium and was seen in the 30(55\%) of cases. Fibrocystic change (Fig. 1a) was seen in $8(14.5 \%)$ of cases. There were two $(3.6 \%)$ cases of complex fibroadenoma, one case showed foci of sclerosing adenosis and one showed cyst of $4 \mathrm{~mm}$ size diameter. There were 3(5.5\%) cases which showed foci of tubular adenoma (Fig.1d). Epithelial hyperplasia was seen in 5(9\%) cases of which two were mild, two were moderate and one was atypical hyperplasia (Fig. 1c). Two cases showed phylloides like areas (Fig. 1b). Fibrocollagenous change was the commonest stromal change observed in fibroadenoma and was seen in $12(22 \%)$ cases. One case showed hyaline stromal change while 4 showed myxoid change. Stromal inflammatory infiltrate was seen in 24(44\%) of cases of which 22 showed lymphocyte and plasma cell infiltrate while two cases showed infiltration by neutrophils as well. 


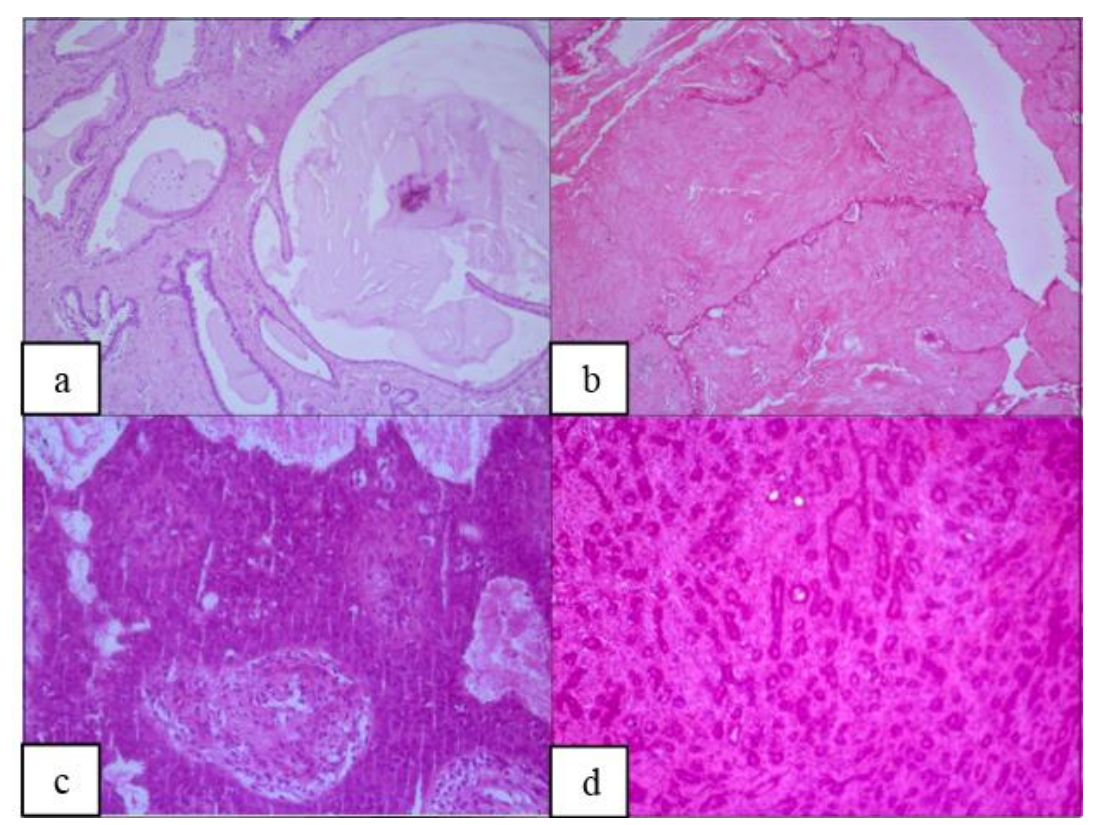

Fig. 1: Changes in fibroadenoma (Hematoxylin and Eosin stain, 400x). a) Fibrocystic change; b) phylloides like area; c) atypical epithelial hyperplasia; d) foci of tubular adenoma

Table1: Histopathological changes observed in 55 cases of fibroadenoma

\begin{tabular}{|l|c|}
\hline \multicolumn{1}{|c|}{ Lesion } & No.(\%) of cases \\
\hline Proliferative epithelial lesion & \\
\hline Mild ductal hyperplasia & $02(3.6 \%)$ \\
\hline Moderate ductal hyperplasia & $02(3.6 \%)$ \\
\hline Atypical ductal hyperplasia & $01(1.8 \%)$ \\
\hline Fibrocystic epithelial changes & \\
\hline Apocrine metaplasia & $30(30 \%)$ \\
\hline Cysts & $08(14.5 \%)$ \\
\hline Sclerosingadenosis & $01(1.8 \%)$ \\
\hline Stromal changes & \\
\hline Fibrocollagenous & $12(22 \%)$ \\
\hline Hyaline & $1(1.8 \%)$ \\
\hline Myxoid & $4(7.3 \%)$ \\
\hline Other & \\
\hline Foci of tubular adenoma & $3(5.5 \%)$ \\
\hline Foci of phylloides tumor & $2(3.6 \%)$ \\
\hline Foci of sclerosing adenosis & $1(1.8 \%)$ \\
\hline Stromal inflammatory infiltrate & \\
\hline Chronic(lymphocytes, plasma cells) & $22(40 \%)$ \\
\hline Acute (neutrophils) and chronic & $02(3.6 \%)$ \\
\hline
\end{tabular}

\section{Discussion}

In the present study majority of fibroadenoma cases were in $3^{\text {rd }}$ decade followed by $2^{\text {nd }}$ and $4^{\text {th }}$ decade. Majority of cases showed right side involvement and pericanalicular pattern similar to other studies.,10 However, side and pattern of involvement do not carry any clinical or prognostic significance.

There are various case reports of juvenile fibroadenoma. ${ }^{11,12}$ In the present study $10(18 \%)$ cases were in adolescent age group. The size of tumor in these cases was less than $5 \mathrm{~cm}$ and there was no history of rapid growth distinguishing them from juvenile fibroadenoma. Nikumbh et al. discussed bilateral giant juvenile fibroadenoma in a 12 year old girl. ${ }^{11}$ Stanford school of medicine describes juvenile fibroadenoma of breast as circumscribed, often large breast mass usually seen in adolescent females with hypecellularity of stroma and epithelium but lacks the leaf like growth pattern seen in phyllodes tumor. ${ }^{13}$ In the present study none of the cases met the criteria of juvenile fibroadenoma and the cases were typical fibroadenoma.

Complex fibroadenoma has one or more feature of sclerosing adenosis, epithelial calcification, cyst greater than $3 \mathrm{~mm}$ in diameter or papillary apocrine change. ${ }^{1}$ 
Sclerosing adenosis which is seen as benign breast lesion is lobulocentric and consist of enlarged and distorted tubules and stromal fibrosis. Visscher et al. noted that sclerosing adenosis doubles the risk of breast cancer if there is no other proliferative lesion in the breast or any family history of breast cancer. ${ }^{14}$ In the present study 2(3.6\%) case were of complex fibroadenoma. One showed features of sclerosing adenosis and other showed a cyst of $4 \mathrm{~mm}$ diameter. Dupont et al. highlighted the increased risk of complex fibroadenoma as 3.1 times of invasive breast carcinoma to women with exclusive fibroadenoma in general population. ${ }^{1}$ However, other studies like to differ and recommend management of complex fibroadenoma similar to simple fibroadenoma. ${ }^{3,15}$

Fibroadenoma with foci of phlloides tumor was noted in 2(3.6\%) cases. Noguchi et al. have documented progression of fibroadenoma to phylloides by clonal expansion of stromal components. ${ }^{9}$ Phylloides have a tendency to recur and hence entails the necessity for wide excision of the lesion. ${ }^{2}$

There were $3(5.5 \%)$ cases which showed foci of tubular adenoma where there was glandular proliferation with little intervening stroma. ${ }^{6,7}$ All the females were less than 25 years of age. Different studies also noted the same histological change., ${ }^{2,45}$

Apocrine metaplasia and fibrocystic change was the most common epithelial change which was seen in the present study. Other studies also showed the same. ${ }^{2,4}$

Most frequent stromal change observed was fibrocollagenous in $12(22 \%)$ cases. Hyaline and myxoid change was also seen as noted in other studies. ${ }^{2,4,5}$ Stromal inflammatory infiltrate was frequently observed chiefly comprised of lymphocytes and plasma cells. However, in two cases neutrophils were also seen. Inflammatory infiltrate can be attributed to prior fine needle aspiration procedure.

Proliferative breast disease usually show epithelial hyperplasia. In mild hyperplasia there is three to four cell layers of epithelial cells. Moderate hyperplasia has more than three cell thickness of epithelium. In severe/florid hyperplasia the duct lumen is appreciably enlarged and may be obliterated or filled with cells. Atypical hyperplasia in addition to eptithelial hyperplasia has cytological atypia. ${ }^{16}$ Study conducted by Hartmann et al. showed that the risk of breast carcinoma increases substantially when proliferative breast diseases is associated with atypia. ${ }^{17}$ Wagoner et al. found that atypical ductal hyperplasia present in more than 2 foci in core needle biopsy was a strong predictor of ductal carcinoma in situ. ${ }^{18}$ Similar to surrounding breast parenchyma, epithelial hyperplasia can be seen in fibroadenomas. In the present study epithelial hyperplasia was seen in $5(9 \%)$ of fibroadenoma cases. Out of these 2 were mild, 2 were moderate and one was atypical. Epithelial hyperplasia poses as risk factors for breast carcinomas in which atypia is of considerable importance. . $^{1,3,8}$

Literature is available where there is malignant transformation of fibroadenoma. The transformation can be into malignant phylloides or into ductal carcinoma. ${ }^{19-21}$ Abe et al. found that of total malignant phylloides in their study, $30.6 \%$ were previously diagnosed fibroadenoma. ${ }^{19}$ So, there is need for careful interpretation/evaluation of histology of fibroadenoma.

\section{Conclusion}

Fibroadenoma showed variety of histological changes of which complex fibroadenoma and epithelial hyperplasia is significantly important which requires appropriate management and follow up.

\section{References}

1. Dupont WD, Page DL, Parl FF, Vnencak-Jones CL, Plummer WD Jr, Rados MS, et al. Long-term risk of breast cancer in women with fibroadenoma. $N$ Engl J Med. 1994;331:10-5.

2. Kuijper A, Mommers EC, van der Wall E, van Diest PJ. Histopathology of fibroadenoma of the breast. Am J Clin Pathol. 2001;115:736-42.

3. Nassar A, Visscher DW, Degnim AC, Frank RD, Vierkant RA, Frost M, Radisky DC, Vachon CM, Kraft RA, Hartmann LC, Ghosh K. Complex fibroadenoma and breast cancer risk: a Mayo Clinic Benign Breast Disease Cohort Study. Breast Cancer Res Treat. 2015;153:397-405.

4. Zakaria F, Ahmed S. histological; variations in fibroadenoma breast. International Journal of Biomedical Research. 2016;7:760-64.

5. Geethamala K, Vani BR, Murthy VS, Radha M. Fibroadenoma: a harbor of various histopathological changes. Clin Cancer Investig J. 2015;4:183-87.

6. Salemis NS, Gemenetzis G, Karagkiougis G, Seretis C, Sapounas K, Tsantilas V, Sambaziotis D, Lagoudianakis E. Tubular adenoma of the breast: a rare presentation and review of literature. J Clin Med Res. 2012;4:64-67.

7. Efared B, Sidibe IS, Abdoulaziz S, Hammas N, Chabani L, Fatenu HE. Tubular adenoma of breast: a clinicopathological study of a series of 9 cases. Clin Med Insights Pathol. 2018;11

8. Shabtai M, Saavedra-malinger P, Shabtai EL, Rosin D, Kuriansky J, Ravid-megidao M, Haim MB, Ayalon AH. Fibroadenoma of the breast: analysis of associated pathological entities-a different risk marker in different age group for concurrent breast cancer. IMAJ. 2001;3:813-17.

9. Noguchi S, Yokouchi H, Aihara T, Motomura K, Inaji H, Imaoka S, et al. Progression of fibroadenoma to phyllodes tumor demonstrated by clonal analysis. Cancer. 1995;76:1779-85.

10. Ajitha MB, Srinivasan N, Shivaswamy BS, Vijaykumar A. A systematic study of fibroadenoma of the breast. IJBAR. 2012;3:891-94.

11. Nikumbh DB, Desai SR, Madan PS, Patil NJ, Wader JV. Bilateral giant juvenile fibroadenoma of brests: a case report. Pathology research international. 2011; 2011: 482046.

12. Ng WK, Mrad MA, Brown MH. Juvenile fibroadenoma of the breast: treatment and literature review. Can J Plast Surg. 2011;19:105-107. 
13. R. L. Kempson and R. V. Rouse. "Juvenile fibroadenoma of the breast," Stanford school of medicine, http.//surgpathcriteria.stanford.edu/breast/juvenile fibroadenoma/.

14. Visscher DW, Nassar A, Degnim AC, Frost MH, Vierkant RA, Frank RD et al. Sclerosingadenosis and risk of breast cancer. Breast Cancer Res Treat. 2014; 144: 205-212.

15. Sklair-Levy M, Sella T, Alweiss T, Cracium I, Libson E, Mally B. Incidence and management of complex fibroadenomas. AJR. 2008;190:214-218.

16. Rosen PP. Rosen's breast pathology. $3^{\text {rd }}$ ed. Philadelphia: Lippincott williams and wilkins, 2009. Chapter 9: Ductal hyperplasia: usual and atypical; p.231-262.

17. Hartmann LC, Sellers TA, Frost MH, Lingle WL, Degnim AC, Ghosh k, et al. Benign breast disease and risk of breast cancer. $N$ Eng J Med. 2005;353:229-237.

18. Wagoner MJ, Laronga C, Acs J. Extent and histological pattern of atypical ductal hyperplasia present on core needle biopsy specimen of breast can predict ductal carcinoma in situ in subsequent excision. AJCP. 2009;131:112-121.
19. Abe M, Miyata S, Nishimura S, Iijima K, Makita M, Akiyama F, Iwase T. Malignant transformation of breast fibroadenoma to malignant phyllodes tumor: long term outcome of 36 malignant phyllodes tumors. Breast cancer. 2011;18:268-272.

20. Chintamani, Khandelwal R, Tandon M, Yashwant K, Kulshrestha P, Aeron T, et al. Carcinoma developing in a fibroadenoma in a woman with a family history of breast cancer: a case report and review of literature. Cases Journal. 2009;2:9348.

21. Sanders LM, Daigle ME, Tortora M, Panasiti R. Transformation of benign fibroadenoma to malignant phyllodes tumor. Actaradiologica. 2015; 4:1-3. 